\title{
Condições de vida, acesso às políticas e racismo institucional em comunidades quilombolas
}

\section{Living conditions, access to policies and institutional racism in quilombola communities}

\author{
João Paulo Macedo (orcid.org/0000-0001-6151-3422)1 \\ Candida Dantas (orcid.org/0000-0003-4778-9400)2 \\ Magda Dimenstein (orcid.org/0000-0002-5000-2915) 3 \\ Jáder Leite (orcid.org/0000-0002-6045-531X)4 \\ Antônio Alves Filho (orcid.org/0000-0001-8370-1096) ${ }^{5}$ \\ Victor Hugo Belarmino (orcid.org/0000-0002-4102-3351)6
}

\begin{abstract}
Resumo
Partimos das problematizações em torno do racismo institucional em que vivem as comunidades quilombolas no Brasil. Para tanto, objetivamos com este estudo: a) identificar o perfil da população, as condições de vida e de acesso às políticas públicas; e b) mapear as linhas de força que compõem as subjetividades e suas histórias de luta. A pesquisa foi realizada numa comunidade quilombola do Estado do Rio Grande do Norte. Os dados foram produzidos a partir da aplicação de questionário sociodemográfico ambiental para os moradores, acompanhado de observação do cotidiano da comunidade e entrevista semiestruturada com as lideranças. Os resultados indicam os efeitos do racismo institucional na produção das iniquidades e desigualdades. Portanto, entendemos o racismo institucional como um bem-sucedido mecanismo da biopolítica ao produzir subjetividades que paradoxalmente sobrevivem entre a captura e a resistência aos propósitos de intervenção e controle social pelas estruturas de poder e domínio do Estado.
\end{abstract}

Palavras-chave: Comunidades quilombolas. Racismo institucional. Biopolítica.

\footnotetext{
${ }^{1}$ Universidade Federal do Delta do Parnaíba, Parnaíba, Brasil. E-mail: jpmacedo@ufpi.edu.br.

2 Universidade Federal do Rio Grande do Norte, Natal, Brasil. E-mail: candida.dantas@gmail.com.

${ }^{3}$ Universidade Federal do Rio Grande do Norte, Natal, Brasil. E-mail: mgdimenstein@gmail.com.

${ }^{4}$ Universidade Federal do Rio Grande do Norte, Natal, Brasil. E-mail: jaderfleite@gmail.com.

${ }^{5}$ Universidade Federal do Rio Grande do Norte, Natal, Brasil. E-mail: antonioalvesfil@gmail.com.

${ }^{6}$ Universidade Federal do Rio Grande do Norte, Natal, Brasil. E-mail: victorbelarmino@outlook.com.
} 


\begin{abstract}
We start from the problematizations around the institutional racism in which the quilombola communities live in Brazil. To this end, we aim with this study: a) to identify the profile of the population, the living conditions and access to public policies; and b) to map the lines of force that make up the subjectivities and their stories of struggle. The research was conducted in a quilombola community in the state of Rio Grande do Norte. The data were produced by applying an environmental sociodemographic questionnaire to the residents, accompanied by observation of the daily life of the community and semi-structured interview with the leaders. The results indicate the effects of institutional racism on the production of inequities and inequalities. Therefore, we understand institutional racism as a successful mechanism of biopolitics to produce subjectivities that paradoxically survive between capture and resistance to the purposes of intervention and social control by the structures of power and domain of the State.
\end{abstract}

Keywords: Quilombola communities. Institutional racism. Biopolitics.

Neste artigo, partimos do mapeamento de algumas linhas de força que compõem as subjetividades, os territórios de vida e de lutas constituintes das comunidades quilombolas. Optamos por retomar esse debate perfazendo um caminho diferente dos estudos que comumente se centram sobre as identidades dos povos remanescentes de quilombos, ou simplesmente povos quilombolas, no âmbito da Psicologia. Entendemos que são trabalhos que guardam bastante mérito ao abordar o tema a partir do resgate de como os elementos identitários dos povos investigados foram forjados a partir das relações de pertencimento, origem, reconhecimento, sistema de crenças e da memória coletiva de um povo/grupo social particular (Furtado, Pedroza \& Alves, 2014; Rabinovich \& Bastos, 2007; Valentim \& Trindade, 2011). Desse modo, propomos contribuir com o debate a partir dos agenciamentos das subjetividades quilombolas, engendradas por meio do investimento nas políticas de direitos, conquistadas nas últimas décadas, mas que se encontram ameaçadas, desde o Golpe que resultou no impeachment de Dilma Rousseff, passando pelo ilegítimo Governo de Michel Temer, e pelo Governo ultraneoliberal e (neo)conservador de Jair Bolsonaro, que avançam com propostas de retirada de direitos no Congresso Nacional e demais setores da sociedade. 
Nosso argumento ancora-se, como ponto de partida, na compreensão de Deleuze e Guattari (1996) a respeito do papel do Estado e suas segmentaridades concêntricas na formação das relações entre sociedade/instituições e suas reverberações nos sujeitos e subjetividades. Para os autores, somos seres segmentarizados espacial e socialmente por linhas molares e moleculares que operam nos planos macro e micropolíticos. No plano molar, os investimentos partem de modelos pré-configurados que demarcam o modo como as estruturas, os arranjos institucionais, as relações sociais, bem como os sujeitos e grupos sociais, por meio de suas percepções, sensibilidade e afetos são organizados e sobrecodificados (Guattari \& Rolnik, 2005). Como desdobramento, desejamos, planejamos e intencionamos a vida com base naquilo que as formações discursivas molares e os agenciamentos políticos e culturais de uma determinada época admitem como possível. Assim, agimos e nos movimentamos politicamente de acordo com os esquemas apriorísticos de ação estabelecidos em certo período histórico (Santana \& Moura, 2013). Entretanto, o plano molecular dos afetos não para de agitar e pôr em movimento os segmentos molares, descodificando-os e admitindo novas políticas de percepção, afecção, do dizer e do agir, que por sua vez resistem e fazem deslocar e modificar os binarismos que nos pré-definem, inclusive provocando experimentações e variações das formas e domínio de intervenção da ação política e, consequentemente, de nós mesmos (Ferreira-Neto, 2015).

O Estado, a partir desse aporte analítico, atua como uma caixa de ressonância de poderes nos planos macro e micropolítico, pois, além de demarcar e sobrecodificar espaços, também produz subjetividades a partir de segmentos pré-determinados que operam por organizações binárias, duais e homogeneizantes (Deleuze \& Guattari, 1996). As políticas públicas com suas gramáticas, diagramas de força e campos de intervenção, acabam estabelecendo determinadas relações que, ao garantir direitos e reduzir desigualdades (ou acomodá-la no parâmetro do aceitável), viabilizando acessos a serviços, programas, benefícios e ações de desenvolvimento social, também reproduzem e atualizam, em certa medida, práticas clientelistas/assistencialistas ou de controle, regulação e de gestão de condutas, a partir da normalização das identidades de determinados grupos sociais para 
que atendam ao formalismo tecnoburocrático e procedimental da ação estatal e seus agentes (Nunes, 2010).

As comunidades quilombolas, enquanto formas de coletivização de resistências no Brasil, estão imersas, portanto, em um campo de tensão e lutas em constante (re)ordenamento. Pretendemos percorrer o engendramento de algumas dessas fronteiras e a constituição desses territórios, que são físicos e subjetivos, a partir de uma reflexão sobre a política pública, sua constituição e apresentação na atualidade. Assim, tomaremos como objeto de discussão e análise as condições de vida e vulnerabilidade que marcam o cotidiano de uma comunidade quilombola situada em um estado do Nordeste brasileiro. Pretendemos dar visibilidade a essa maquinaria estatal e suas políticas que, alimentadas pelo racismo institucional, produzem novos parâmetros identitários e de reconhecimento para a coletividade, que se convertem em dispositivos de governo dos corpos e das subjetividades, logo, de controle e regulação da vida.

No cenário atual de ameaças e retrocessos, tem-se o argumento de crise de sustentabilidade dos sistemas de seguridade e de proteção social, acompanhado da queixa para o fortalecimento do aparato de segurança e repressão, em que o Estado brasileiro em sua estratégia biopolítica de gerenciamento da vida hierarquiza necessidades humanas e prioriza acessos a determinadas políticas e recursos, que acabam desenhando quais vidas são objeto de investimento e quais qualifica como "vidas insustentáveis" (Cascais, 2016, p. 195). Assim, "não se trata apenas da definição dos indivíduos ou dos grupos a serem discriminados, excluídos e expurgados, mas da definição dos candidatos elegíveis ao acesso à prestação de cuidados" e quais não (Cascais, 2016, p. 195).

Nas palavras de Mbembe (2017), tal condição exacerba quem pode e quem não pode viver. Política que incide sobre a vida tornando segmentos da população como supérfluo e excedente da sociedade, restando-Ihes, portanto, a expulsão, o confinamento ou o extermínio. É o que temos visto no Brasil atual, a título de exemplo, com as ações sistemáticas de extermínio e genocídio da juventude negra nas periferias das grandes cidades e com os conflitos no campo e áreas de preservação e conservação ambiental. 


\section{As comunidades quilombolas e a política pública}

Os territórios quilombolas ganharam visibilidade e legalidade a partir da Constituição de 1988, em consequência das ações promovidas pelos movimentos sociais negros e da atuação de alguns parlamentares envolvidos com a causa do reconhecimento e garantia dos direitos das comunidades rurais negras (Cardoso \& Gomes, 2011; Carvalho, 2016). Tais investimentos, de acordo com López (2012, p. 125), se inserem em uma luta ampla para garantir maior "permealibilidade da temática racial no Estado Brasileiro", a partir de alguns momentos que foram decisivos para causa negra (antirracista) no país.

Destacam-se, como primeiro momento, as comemorações do centenário da abolição ocorridas concomitante ao movimento da Constituinte de 1988. Na oportunidade, foram criados conselhos, assessorias e órgãos voltados para tratar de questões específicas da população negra, cuja ação mais importante foi a criação da Fundação Cultural Palmares, vinculada ao Ministério da Cultura. Essa Fundação, hoje sob ataque e interesses contrários às causas da população negra e quilombola, foi criada com o intuito de promover e preservar a arte e da cultura afro-brasileira. É nesse contexto que as demandas da população negra rural sofrem um processo de ressignificação pela emergência, na Carta Magna de 1988, em que o termo "remanescente de Quilombo" pressupõe o reconhecimento e a proteção pelo Estado do direito territorial e do patrimônio cultural das comunidades quilombolas no Brasil (Bargas, Rocha \& Cardoso, 2015; Leite, 2008).

Um segundo momento foi a "Marcha Zumbi dos Palmares Contra o Racismo", ocorrida em 1995, em Brasília, organizada pelos movimentos negros em nível nacional. As reivindicações resultaram na criação de um grupo de trabalho interministerial com o objetivo de elaborar políticas para a população negra. Apesar dos canais de diálogo que foram abertos, López (2012) indica que não se avançou concretamente pós-Constituição na consolidação de políticas sociais visando ampliar o acesso e as oportunidades de redução das desigualdades sociais e raciais que atingem a população negra no Brasil. Um dos fatores que contribuiu para essa questão foi o fato de que a proposição de políticas de direitos nesse período teve como pano de fundo a gradativa implantação de políticas e práticas 
neoliberais no Brasil, com uma agenda que desestatiza, desregulamenta e desuniversaliza direitos (Carvalho, 2009). Isso implicou na falta de respostas por parte do Estado frente ao amplo e complexo campo da "questão social" que impera no Brasil e, consequentemente, das necessidades da população negra, particularmente, dos povos quilombolas.

O terceiro momento ocorre no período do Governo Lula (2003-2010), em que se estabeleceu uma nova relação entre o Estado e os movimentos sociais minoritários com a criação de políticas públicas para diferentes grupos sociais que se concebiam como sujeitos identitários que reivindicam direitos. No âmbito das lutas pela causa negra, López (2012) assinala o papel da $3^{\mathrm{a}}$ Conferência Mundial das Nações Unidas contra o Racismo, a Discriminação Racial, a Xenofobia e as Formas Conexas de Intolerância, dando destaque ao desenvolvimento de ações afirmativas nas agendas das políticas públicas dos países. Isso motivou no primeiro ano do governo Lula a criação da Secretaria Especial de Políticas de Promoção da Igualdade Racial (Seppir) para a proposição de uma política de promoção da igualdade racial de caráter transversal.

Em relação aos povos quilombolas foi aprovado o Decreto n. 4.887, de 20 de novembro de 2003, que regulamenta o procedimento para identificação, reconhecimento, delimitação, demarcação e titulação das terras ocupadas pelos chamados povos "remanescentes de quilombos". Após vários anos de conflitos sobre a definição da responsabilidade por tais processos, coube à Fundação Cultural Palmares o reconhecimento, por envolver aspectos relacionados ao patrimônio cultural dos povos quilombolas. Já a titulação das terras quilombolas coube ao Instituto Nacional de Colonização e Reforma Agrária (Incra), responsável pelos processos de reforma agrária no país. Em seguida foi aprovado o Plano Brasil Quilombola (Brasil, 2004), que teve como objetivo consolidar os marcos da política de Estado para as áreas quilombolas, seguido da Política Nacional de Desenvolvimento Sustentável dos Povos e Comunidades Tradicionais - PNPCT (Brasil, 2007a) e da Agenda Social Quilombola (Brasil, 2007b), que propôs ações estratégicas em diferentes setores e políticas para garantir o acesso à terra, infraestrutura e qualidade de vida, inclusão produtiva e desenvolvimento local, abrindo campos de direitos e cidadania para essa população. 
Existem atualmente no Brasil por volta de 3.168 comunidades quilombolas, sendo que apenas 218 destas estão tituladas com suas terras, o equivalente apenas a 8,7\% do total de comunidades quilombolas certificadas no país7. A certificação consiste no reconhecimento legal da autodefinição de remanescente de quilombola, ou seja, como "grupo étnico-racial, segundo critérios de autoatribuição, com trajetória histórica própria, dotada de relações territoriais específicas, com presunção de ancestralidade negra relacionada com a resistência à opressão histórica sofrida" (Brasil, 2003, p. 1). Já a titulação refere-se à obtenção do título oficial da terra ocupada por povos quilombolas e "utilizadas para sua garantia da reprodução física, social, econômica e cultural" (Brasil, 2003, p. 1). Apesar dessas garantias, é perceptível que o processo de titulação é mais lento e burocrático. Segundo Oliveira e D’Abadia (2015), tal fato se deve tanto à burocratização dos processos administrativos vinculados à titulação quanto aos jogos políticos e de interesses econômicos dos grandes fazendeiros e/ou empresários rurais.

Atualmente, em meio às políticas de orientação neoliberal instaladas no Brasil desde o início dos anos 1990 e aprofundadas mais recentemente nos governos Michel Temer e Jair Bolsonaro, de orientação ultraneoliberal e (neo)conservadora, temos vivido um grave quadro de desmonte das políticas sociais e retrocesso diante das conquistas alcançadas. Nesses termos, o processo de reconhecimento e, especialmente, de titulação das comunidades quilombolas esbarra nos limites administrativos e burocráticos operados nos diversos setores governamentais. Além disso, são processos que sofrem com os entraves do contexto de lutas e disputas pela regularização fundiária que marcam o cenário rural brasileiro. Para Sauer (2016), tais conflitos resultam de um longo processo histórico que institui um modelo agropecuário e agrário de concentração de terra nas mãos dos grandes proprietários, e consequente expropriação no acesso às terras pelas populações pobres, incluindo os escravos libertos desde 1888, e até mesmo segmentos dos emigrantes europeus.

Todas essas barreiras históricas podem estar associadas ao racismo institucional, o qual é parte das forças que transversalizam as políticas sociais para essa população, em sua

\footnotetext{
7 Informações disponíveis em www.palmares.gov.br
} 
configuração institucional e não apenas individual. Esse é o ponto que queremos destacar neste debate. Para López (2012), a partir dos estudos foucaultianos, é o próprio Estado, apoiado na racionalidade biopolítica de governo, que assumiu historicamente e legitima ainda hoje aquilo que a literatura tem denominado por racismo institucional.

Trata-se da forma difusa de funcionamento cotidiano de instituições e organizações, que operam de forma diferenciada na distribuição de serviços, benefícios e oportunidades aos diferentes segmentos da população do ponto de vista racial. Ele extrapola as relações interpessoais e instaura-se no cotidiano institucional, inclusive na implementação efetiva de políticas públicas, gerando, de forma ampla, desigualdades e iniquidades. (López, 2012, p. 127).

O racismo de Estado apresenta-se como um conjunto de discursos e práticas constituintes da sociedade e de suas instituições. Expressa-se como estratégia biopolítica por meio de técnicas de controle, gerenciamento e assujeitamento das populações a partir de um amplo diagrama de poderes firmado pelo poder médico que incide sobre a saúde dos grupos sociais, pelo poder purificador da raça, pelo dispositivo da sexualidade, dispositivo de segurança e governo econômico (Farhi Neto, 2008).

Nesses termos, o racismo institucional atua como importante instrumento garantidor da normalização e integração social nos mais diferentes âmbitos: estrutural, no campo das políticas públicas e de programas, projetos e ações. Como "mecanismo performativo ou produtivo" (Werneck, 2013, p. 17), conta, cada vez mais, com estratégias seletivas de privilegiamento e barreiras capazes de gerar e legitimar condutas excludentes, de constituição de sujeitos e de produção de subjetividades.

Para o referido autor, o conjunto de políticas fragmentadas ofertadas pelo Estado, na tentativa de estabelecer padrões mínimos de igualdade e estabilidade social, não tem conseguido superar outro conjunto de iniquidades que também se apresentam estruturais à sociedade brasileira. As políticas de promoção da igualdade racial, para as mulheres, para a juventude, para o acesso à terra e à regularização fundiária, enfim, para os povos tradicionais em geral são exemplos disso. Tal realidade acaba por perpetuar iniquidades 
associadas às desigualdades econômicas e à discriminação racial, legitimadas historicamente pelo próprio Estado (Werneck, 2013).

Apesar das garantias conquistadas e o respaldo das políticas públicas de proteção social e desenvolvimento social, os povos quilombolas e a população negra em geral têm seus direitos violados cotidianamente, seja pelas condições precárias de vida a que são submetidos, seja pela ameaça constante do seu território, decorrente das disputas políticas envolvendo grandes proprietários de terra ou de setores do próprio Estado.

Evidencia-se, portanto, as capturas advindas da própria maquinaria estatal, por meio das políticas públicas, que apesar de reconhecer direitos, inclusive de grupos minoritários, reproduz desigualdades, assujeitando indivíduos e grupos sociais, ao demarcar determinadas condições e critérios de acesso a certos serviços, programas sociais e garantias legais, ou critérios de abandono de investimento de ações para determinados grupos. Trata-se de uma racionalidade do Estado, cujas tecnologias hierarquizam populações entre boas e más raças, ou conjuga a maximização da vitalidade e da força/capacidade produtiva de uns com a exclusão, o esquecimento e a invisibilidade de outros (Caponi, 2016). Como aponta Duarte (2008), a descoberta de uma política do racismo como forma privilegiada de atuação estatal não é um fenômeno do passado, ao contrário, perpetua-se nas ações e modos de funcionamento contemporâneos, mesmo em um cenário de relativos avanços do ponto de vista legal e institucional no campo dos direitos.

Com base nessa perspectiva, pretendemos dar visibilidade a essas questões a partir de um estudo realizado em uma comunidade quilombola localizada na região agreste do Rio Grande do Norte. Objetiva-se identificar o perfil da população, as condições de vida e os acessos às políticas públicas da comunidade quilombola investigada; e mapear as linhas de força que compõem as subjetividades e os territórios de vida em meio as lutas que marcaram/marcam a comunidade investigada.

\section{Método}


O presente estudo é parte de uma pesquisa maior realizada em uma comunidade quilombola rural da região agreste do RN, com o objetivo de conhecer as condições de vida, saúde e trabalho da população, bem como investigar a incidência de transtornos mentais comuns e os padrões do uso de álcool entre os moradores da comunidade. Neste artigo, delineamos um estudo transversal que contou com a estratégia metodológica explanatória sequencial (Creswell, 2007), conjugando etapas de natureza quantitativa e qualitativa.

Para efeito do presente artigo, apresentaremos parte dos dados produzidos a partir do uso de três ferramentas por meio dos seguintes procedimentos: 1. Uso de questionário sociodemográfico ambiental com os membros das 64 famílias moradoras (196 participantes), que versou sobre dados gerais da comunidade e da população investigada: sexo, idade, estado civil, escolaridade, tipos de ocupações, renda, condições de moradia e habitação, agravos de saúde, acesso aos serviços de saúde, assistência social e assistência técnica rural. Sob a perspectiva censitária, participaram da pesquisa pessoas maiores de 18 anos, que estavam presentes nos domicílios no momento da coleta de dados e aceitaram participar da pesquisa. 2. Entrevista semiestruturada com dois informantes-chave (lideranças). 3) Observação da realidade local. A entrevista e a observação serviram para identificar a dinâmica social e as formas de organização da comunidade, suas dificuldades em relação ao acesso às políticas públicas e anseios dos moradores em relação às condições de vida, trabalho, saúde e moradia. O foco da entrevista com as duas lideranças da comunidade justifica-se porque foram as pessoas que protagonizaram o processo de organização comunitária, especialmente por meio da gestão de uma associação existente no local.

A análise dos resultados produzidos a partir dos dados do questionário foi com base na análise descritiva da frequência absoluta, relativa e mediana (valor mínimo e máximo), enquanto das entrevistas e observações tomaram por base a análise temática de conteúdo proposta por Minayo (2007). No caso do tratamento qualitativo, tomamos como referência as etapas de pré-análise, exploração do material ou codificação e tratamento dos resultados (interpretação), resultando nos seguintes eixos analíticos: histórico da comunidade, processo de luta e conquista do reconhecimento, acesso às políticas públicas, participação 
política dos moradores, equipamentos sociais, práticas religiosas, manifestações étnicoculturais, conflitos comunitários e expressões do racismo institucional.

Por fim, os procedimentos éticos em pesquisa foram observados com base nas Resoluções do Conselho Nacional de Saúde de n. 466/12 e n. 510/16, tendo todos os participantes assinado o Termo de Consentimento Livre Esclarecido.

\section{Resultados}

Perfil da população, condições de vida e acesso às políticas públicas

De acordo com a Fundação Cultural Palmares, há no Brasil 3.168 Comunidades Quilombos em todo o país. No entanto, esse número pode ser ainda maior, considerando que existem muitas comunidades que ainda não foram mapeadas por estarem isoladas geograficamente ou mesmo que não se reconhecem como quilombolas (Neiva et al., 2008). O Nordeste é a região que agrupa o maior número de comunidades reconhecidas no país (62\%). No Rio Grande do Norte há somente 23 territórios quilombolas, sendo o estado do Nordeste com menor número de comunidades certificadas da região. A comunidade-alvo desta investigação encontra-se na zona rural, distante $6 \mathrm{~km}$ da sede do município, que segundo dados do IBGE do ano de 2016 tem uma população de 10.185 habitantes.

Das 196 pessoas respondentes, 90 são do sexo masculino $(45,9 \%)$ e 106 do feminino $(54,1 \%)$, com média de idade de 30,33 anos (desvio padrão $\pm 20,2$ ) e uma variação que vai de 1 a 90 anos. Se considerarmos os grupos etários da comunidade, o destaque é para crianças e adolescentes (0-17 anos, 34,9\%), seguido dos adultos na faixa de 30-49 anos, com 29,3\%. Os dados nacionais do levantamento do Ministério do Desenvolvimento Social (MDS), em relação às Comunidades Quilombolas (Brasil, 2014), apontam para a predominância da população masculina nos territórios $(51,72 \%)$. Porém, na realidade do Nordeste, a predominância é de mulheres, muitas das quais assumem a função de chefe de família. Isso exige das políticas públicas um olhar mais sensível para determinadas comunidades, cujas condições podem gerar potenciais desigualdades e quadros de 
vulnerabilidade entre homens e mulheres, notadamente em relação às condições de trabalho e de vida, de acesso e controle dos recursos e benefícios sociais.

É interessante observar também a participação e protagonismo das mulheres nos movimentos organizativos das comunidades quilombolas, mesmo diante de um cenário em que as desigualdades de gênero limitam a ocupação de espaços de representação política na sociedade por mulheres, especialmente, as negras (Biroli, 2018). Na comunidade investigada, os lugares de liderança e o envolvimento, como os processos de luta e reivindicação por direitos, foram ocupados historicamente por mulheres.

Porque os "homem" só quando faz projeto, só quer o dinheiro, ele acha que o dinheiro tem que vir e ficar na mão dele e não adianta as "mulher" vir dizer que é pra trabalhar e daquele dinheiro tirar o futuro, tirar lucro, né. Aí eles não querem, eles querem é o dinheiro. As "mulher" não dá o dinheiro porque a maioria dos "homem" bebe. Então pra que associação? Pra que projeto? Projeto é pra botar associação pra frente, pra se ter futuro, pra ter trabalho, todas essas coisas. (Liderança 1).

A percepção das lideranças entrevistadas é de que os homens não compreendem os recursos da associação como parte de um projeto comunitário, mas para satisfazer necessidades individuais e imediatas. Esse certamente é um fator gerador de conflitos que atualizam tensões e embates entre homens e mulheres na comunidade. Para as mulheres, por exemplo, muitas vezes recai a responsabilização pela construção de projetos futuros, ao mesmo tempo em que se coloca em xeque sua autonomia e gestão cotidiana das ações que assumem na comunidade.

Quanto à escolaridade, a maioria tem apenas o ensino fundamental completo ou incompleto $(53,4 \%)$, seguido daqueles que não são alfabetizados ou que sabem escrever apenas o nome, incluindo quem tem somente um ano de escolaridade $(23,8 \%)$. O percentual daqueles que têm o ensino médio (completo ou incompleto) é de $21,7 \%$. Trata-se de um dado que converge com a realidade nacional, considerando que $64,5 \%$ da população quilombola do país, com idade acima de 10 anos, cursaram até o ensino fundamental e $24 \%$ 
são analfabetos. Em algumas realidades como no Centro Oeste, o número de mulheres não alfabetizadas chega a 35\% (Brasil, 2014).

Quanto à renda familiar, a maioria da população vive com uma renda de até 1 salário mínimo (68,8\%), o que aponta para a possibilidade de limitação econômica dessas famílias. A renda é proveniente de múltiplas fontes de sustentação, a partir da combinação da agricultura $(73,4 \%)$ com outras estratégias de complementação de renda, entre as quais destacam-se: programas sociais (46,9\%\%), criação e venda agropecuária $(29,7 \%)$, prestação de serviço (25\%), aposentadoria $(28,1 \% \%)$, e em percentual bem inferior às outras combinações, o trabalho assalariado (12,5\%). A realidade nacional segue a mesma direção, expondo o quadro de pobreza e extrema pobreza nos territórios quilombolas do país. Essa última atinge 45,8\% dos indivíduos quilombolas do Brasil, considerando que o fator renda relaciona-se com outros, por exemplo: condições de moradia e infraestrutura, acesso a serviços públicos, direitos sociais e segurança alimentar e nutricional, dentre outros, caracterizando assim condições de pobreza numa perspectiva multidimensional (Brasil, 2014).

Apesar da reprodução do quadro de fragilidade em relação às questões de moradia e condições de vida observadas nacionalmente, detectou-se a melhoria de alguns indicadores nessa população, em comparação com a realidade nacional, os quais são fruto da maior presença de programas sociais voltados para as populações rurais: Programa Água para Todos (52,4\%), Luz para Todos (58,7\%), Habitação Rural (27\%) e o Programa Minha Casa, Minha Vida (34,9\%). Ainda assim, fica evidente a falta de retaguarda adequada por parte das políticas públicas para a população investigada. O que é ofertado acaba não contemplando a todos, repetindo a lógica focalista e excludente das políticas, apesar do quadro de necessidades.

Quanto ao acesso à equipe/serviços de saúde, 79,9\% são atendidos pelo Agente Comunitário de Saúde, mas somente $75,0 \%$ são atendidos pela ESF na própria comunidade, quando a equipe se desloca para realizar visitas quinzenais. Esses são aspectos que indicam a dificuldade de acesso às políticas de saúde pela comunidade. Poucos fazem uso da medicina popular e práticas religiosas tradicionais. Chama atenção a baixa presença de 
ações que fortaleçam o resgate da memória e do conhecimento de remédios e soluções caseiras para doenças e males que ocorrem na comunidade.

De forma geral, a realidade observada demonstra que as famílias da comunidade estudada enfrentam uma série de vulnerabilidades em função das dificuldades de renda, emprego, educação, transporte, isolamento, consequentemente, de acesso aos serviços e programas de assistência e saúde para o enfrentamento das adversidades que marcam o seu cotidiano. Tal quadro aponta para a necessidade de maior investimento nas políticas públicas voltadas para a população quilombola, sobretudo em função dos avanços das últimas décadas nas diferenciações orçamentárias e critérios de inserção para diversos programas das políticas sociais. No caso da Estratégia Saúde da Família, por exemplo, ter equipes implantadas em comunidades quilombolas acrescenta $50 \%$ do financiamento das equipes. O mesmo critério também se repete para o fortalecimento de recursos para áreas de saneamento básico, alimentação escolar, programa bolsa família, entre outros.

\begin{abstract}
"pra que esses $50 \%$ de repasse nas conta das prefeitura?", pra melhoramento da saúde dos quilombola, pra melhoramento da educação, que as criança do sítio tenham um ensino diferenciado, uma merenda diferenciada, e tenha um atendimento de saúde diferenciado, aí olhe só a diferença, se atendia lá e eles vinha uma vez por semana num grupo escolar que tem ali, quando surgiu a diferença tiraram do grupo e botaram debaixo de um cajueiro, aí pronto, ficou diferente. (Liderança 1)
\end{abstract}

Assim, apesar das ações afirmativas referidas, observa-se uma ausência de investimento e direcionamento das ações por parte dos governos municipais e estadual, considerando a invisibilidade das demandas por parte do poder público, consequentemente, a falta de retaguarda para as comunidades quilombolas do Rio Grande do Norte.

É perceptível, nesse caso, o nível de exclusão com que os aparelhos do Estado tratam as comunidades quilombolas no RN, com a oferta desigual de serviços, benefícios e oportunidades, aprofundando o quadro de desigualdades e iniquidades. Em um contexto de extrema pobreza, baixa escolaridade, falta de trabalho, em que $87,3 \%$ das famílias estão cadastradas no CADÚnico para terem acesso às políticas da Assistência Social, somente $54 \%$ 
é beneficiária do Programa Bolsa Família, isso diz muito do nível de racismo institucional enfrentado por essa comunidade, resultado de ações que hierarquizam as necessidades de determinados grupos sociais, limitando e precarizando significativamente o acesso às políticas públicas.

Nesse sentido, a ideia de racismo institucional nos auxilia na compreensão das dificuldades tanto em relação às barreiras ao avanço nos processos de titulação da terra quanto ao acesso às políticas afirmativas voltadas para essa população. A problemática acerca do reconhecimento social das comunidades quilombolas, quanto à dificuldade de comprovação da ocupação das terras, devido à exigência documental e à desconsideração das narrativas históricas e das memórias dos membros da comunidade, são elementos que revelam a presença do racismo institucional, contribuindo para a perpetuação da invisibilidade histórica dos quilombos.

\section{Territorialidades e produção de subjetividade em comunidades quilombolas}

Para compreender as multiplicidades e heterogeneidades que constituíram os povos quilombolas, inclusive os aspectos que os definem na atualidade, é preciso situar historicamente suas formas organizativas, passando por épocas anteriores à instalação e desenvolvimento da empresa escravista no Brasil. No continente africano, kilombo significava diferentes modelos de organização social, composto por agrupamentos militares e até feiras e mercados (Munanga, 1996).

O quilombo brasileiro no período Colonial e no Império seguiu o mesmo direcionamento dos africanos, formando territórios paralelos de poder, em contraposição ao sistema escravista e de dominação (Calheiros \& Stadtler, 2010; Nascimento, Batista \& Nascimento, 2016). Fugidos das senzalas, plantações e áreas de mineração, logo passaram a ocupar terras não povoadas e de acesso difícil em busca de segurança e proteção. Para Munanga (1996), tais territórios transformaram-se tanto em campos de acolhida para outros grupos e indivíduos oprimidos (mestiços, índios e brancos) quanto de iniciação à luta e resistência, configurando nova forma de organização social e política plurirracial. 
Tal forma de organização nos parece aproximar-se da ideia de máquina de guerra concebida por Deleuze e Guattari (1997) no "Tratado de Nomadologia: a Máquina de Guerra". Tais máquinas são marcadas pela exterioridade à forma de soberania dos poderes e pela irredutibilidade à forma Estado. Tal exterioridade não está apenas relacionada ao aparelho do Estado, mas a ela mesma como máquina de guerra, considerando o potencial de diferença que a constitui. Essas comunidades, chamadas de "sociedades primitivas", eram assim denominadas pelos etnólogos por reunirem algumas características: operarem "sem aparelho de Estado central fixo"; guardar "certa flexibilidade de acordo com as tarefas e as situações"; atuar por "uma grande comunicabilidade entre heterogêneos"; adotar "um código polívoco, fundado nas linhagens, suas situações e suas relações variáveis"; e se constituem por "uma territorialidade itinerante, fundada em divisões locais emaranhadas" (Deleuze \& Guattari, 1997, pp. 84-85).

Munanga (1996) encontra tais características na formação histórica dos quilombos brasileiros no período Colonial e do Império. São formações heterogêneas, pois, apesar de seguirem em sua maioria o modelo bantu, eram constituídos por porosidades que uniam africanos, descendentes de diferentes raízes e descontentes não necessariamente negros, daí seu caráter transcultural. Certamente, tais comunidades afrontavam o modo de organização da forma Estado da máquina escravista brasileira centralizada em segmentaridades duras, binárias e de sobrecodificações unívocas. Ou seja, o quilombo insurgia-se como território de resistência, de luta e ruptura, como máquina de guerra nômade contra a forma Estado do Brasil Colônia e Império.

Em decorrência disso, os povos de quilombos passaram a ser representados e reconhecidos como bárbaros, criminosos, fugitivos, desordeiros, fora da lei, enfim, inimigos da ordem pública. As investidas pelo uso da força e violência perpetrada pelos senhores de escravos, grandes proprietários de terras e representantes da Coroa, acabaram enfraquecendo e reprimindo os principais territórios de luta e resistência quilombola, o maior deles conhecido como Palmares. Porém, há registro quanto a presença de negros exescravizados e de quilombos em movimentos de insurreição organizados em diversas regiões do país, de caráter separatista e com ideias abolicionistas: Alfaiates (Bahia, 1798- 
1799), Cabanagem (Pará, 18351840), Sabinada (Bahia, 1837-1838), Guerra da Balaiada (Maranhão, 18381841) (Gohn, 1995).

Com o aprofundamento da historiografia sobre a população negra no Brasil, sabe-se que nem todos os quilombos no país foram formados de escravos fugitivos e rebeldes. De acordo com Reis e Gomes (1996), há uma diversidade de origens já reconhecidas pelos pesquisadores, que vão desde o abandono da terra pelo fazendeiro-proprietário em situações de crise e perda econômica do produto cultivado, casos de herança para escravos da confiança do fazendeiro-proprietário ou da viúva, casos em que o herdeiro era um filho bastardo, terras doadas a santos, que, posteriormente, foram ocupadas por comunidades negras.

Após o fim da escravidão em 1888, apareceram os chamados quilombos tardios, que foram passando por mudanças no perfil das lideranças e da própria dinâmica da comunidade, em função das aproximações e alianças com demais camadas sociais, muitas vezes marcadas pelo preconceito e discriminação, ou pelo próprio contexto de isolamento que implicou na perda de algumas referências com o passado (Reis \& Gomes, 1996). Um exemplo emblemático é quanto ao credo religioso da maioria das pessoas que vivem em comunidades de quilombolas na atualidade. Nacionalmente, há maior presença de pessoas que se reconhecem católicos (84\%), seguido dos evangélicos/protestantes $(48,5 \%)$ e menor percentual entre aqueles que seguem as religiões de matriz africana (14\%) (Brasil, 2014). No caso da comunidade investigada neste estudo, $75 \%$ são católicos e $11 \%$ protestantes, sem referência às religiões de origem afro entre os respondentes do questionário. Entretanto, as lideranças entrevistadas mencionam algumas práticas relacionadas às religiões de matriz africana, em que as pessoas envolvidas são alvo de desconfiança e preconceito por parte da comunidade.

Depois de um século de silenciamento, entre o período da abolição (1888) e a retomada dos debates acerca da "questão quilombola" nos anos 1970, e com maior força em 1980, veio à tona uma nova discursividade proposta pelo campo das ciências sociais, dos aparelhos do Estado e pelo campo jurídico, pressionado pelos movimentos sociais, em torno da ressignificação e reconhecimento de quem são, quais os direitos e como o Estado 
deve se relacionar com os remanescentes de comunidades de quilombos (Marques \& Gomes, 2013).

A luta, por essas investidas passou a ser política, seguindo aquilo que Foucault (2005, p. 23) no curso "Em defesa da sociedade" referiu, a partir da inversão do aforismo de Clausewitz, que a "política é a guerra continuada por outros meios". A disputa em torno desse novo campo de discursividade abriu novas fronteiras tendo seu significado atual, na opinião de Marques (2008, p.24), como resultado das redefinições e rompimento com as “ideias passadistas", encapsuladas em concepções pré-determinadas pelo Estado, em sua estrutura jurídica colonial e imperial de imposição e dominação de grupos e territórios.

Isso requer, portanto, a apropriação simbólica e autorreconhecimento por parte dos grupos. Muitos são mobilizados por organizações sociais, políticas, religiosas, sindicais, ligadas ao movimento negro e outros movimentos sociais, para se reconhecerem nessa categoria sociológica "remanescentes de quilombo" e, posteriormente, serem reconhecidos pelo Estado, por meio da certificação e conquista de um território, com a titulação da terra que ocupam. Para tanto, basta apresentar algumas dessas características: "definição de um etnônimo, rituais ou religiosidades compartilhadas, origem ou ancestrais em comum, vínculo territorial longo, relações de parentesco generalizado, laços de simpatia, relações com a escravidão e, principalmente, uma ligação umbilical com seu território" (Marques \& Gomes, 2013, p. 142).

No entanto, Silva (2009), em seu estudo sobre a Comunidade Riacho dos Angicos, no Rio Grande do Norte, indicou que a identificação como remanescente de quilombos pode ser permeada de dificuldades: algumas comunidades compreendem a denominação "negro" como símbolo de preconceito e tratamento violento, devido ao passado de escravidão. Há resistência em se autorreconhecerem como tal. Fato semelhante ocorreu na comunidade investigada, pois foi necessária a intervenção das lideranças locais, juntamente com o movimento negro, para que a comunidade se apropriasse da sua história e se sensibilizasse para a luta contra a segregação e preconceito que os marca e determina seus modos de vida. Seguem duas falas acerca disso: 
Nessa época ninguém aceitava ser chamado de "nego". Em Capoeira dizia assim: "ah, os "nego" de capoeira". Quer morrer, diga que é "nego"! Aí agora não, agora eles já aceitam. "Ah, nós vamos lá para os "nego" das Capoeira", né?! "Como foi que eles aceitaram isso?". No início não aceitava não, nem eles e nem nós, foi depois dessa militância, mostrando os conselhos, as palestras. O pessoal vinha muito na comunidade de Capoeira. Aqui tem vindo poucas pessoas. Em Capoeira vinha mais, às vezes era constante, vinham de ônibus pra fazer visita. (Liderança 1).

O negócio é dá apoio. Agora pisou no calo, o caso é diferente. Dizia assim: - "O seu nego". - "Não chama de nego não, se chamar de novo..." Eu, na minha época de mocinha, dizia: - "Se chama de novo de nega de novo ai... Se quiser apanhar, chama de nega de novo! Não tá vendo que sou nega, pra que chamar?". Aí muitas das vezes dizia assim: - "ô morena". Hoje que a gente veio descobrir que moreno não existe, ou é negro ou é branco. Eu aceitei hoje ser negra porque é a minha raça, é a cor da minha pele, tudo isso, é o meu cabelo carapinho. Vixe! Na época ninguém dizia que o cabelo do outro era pixaim não. Vixe, misericórdia! (Liderança 2).

É imprescindível reconhecer que os povos remanescentes de quilombos vivem em uma dinâmica social conflituosa e permeada de deslocamentos e disputas. Há fronteiras geográficas e subjetivas que vão sendo delineadas pelos interesses e relações de poder, as quais interferem na organização do cotidiano e das subjetividades. Inspirado em autores pós-estruturalistas como Gilles Deleuze e Félix Guattari, Haesbaert (2007), propõe como caminho para os estudos territoriais a análise dos processos de territorialização e desterritorialização, ou seja, dos agenciamentos maquínicos que operam máquinas sociais produtoras de novas articulações entre indivíduos, grupos e sociedade. Esses processos podem ser resultados de ações que escravizam e forçam o sujeito a se submeter à desterritorialização e perda de referências, como vimos no passado dos quilombolas no Brasil, ou de resistência, de criação de novos territórios de vida, das ditas "comunidades remanescentes" ou "quilombos contemporâneos".

O processo de formação da comunidade estudada é semelhante ao que ocorreu em grande parte dos territórios remanescentes de quilombolas brasileiros. Segundo o relato de uma das líderes, a origem remonta a outra comunidade, no município vizinho, que foi 
fundada por escravos fugitivos de um engenho. A partir disso, outros fugitivos ou mesmo negros libertos se juntaram à comunidade, como forma de garantir não somente um pedaço de terra para o trabalho agrícola e criação de pequenos animais, mas também um lugar para constituição de novas famílias: “- Os mais antigos diziam vai lá e cerca um pedaço de terra, tu não vai casar? " (Liderança 1).

Furtado, Pedrosa e Alves (2014), ao se referirem sobre a constituição dos "quilombos" brasileiros, ressaltam a importância das relações de solidariedade e parentesco, baseado em laços sanguíneos, de afinidades e de compadrio (simpatia) entre as famílias, além das práticas religiosas e relações com o território como fundamentais na produção desses espaços de resistência. Segundo uma das lideranças entrevistadas,

Eles chegaram no quilombo construíram sua família, tiveram seus netos, bisneto, tataraneto... Daí deu continuação a família, e hoje os neto, bisneto, "escanchaneto" e "trepaneto", somos nós que estamos situados nessas terra sem comprar, por isso que nos se chama quilombo... Quilombola, porque muita gente diz! "E o que é quilombola?" ou "o que é quilombo?". Quilombo é uma terra que era devoluta do governo, eu não comprei e não paguei nada, meu tataravô é quem morava, aí ficou meu bisavô, entendeu? Ai depois ficou meu pai, ficou assim... Aí vai passando. Eu morro e meus filhos ficam. Agora com essa demarcação de título é que a gente tá pretendendo ver se o governo federal reconhece e nos dá o título de reconhecimento. Por enquanto a gente tem só o certificado de identificação quilombola, né? (Liderança 1).

Baseado em Little (2002), pode-se entender que o povoamento da terra e a delimitação das fronteiras, por meio do cercamento, não se trata de uma relação mercantil de propriedade individual, mas para fins de moradia e manutenção da vida e de trabalho, formação de novas famílias para garantir a continuidade dos laços de parentesco e guardar uma memória comum das vivências compartilhadas. Para Silva (2011), as fronteiras, como importante recorte analítico para o estudo do ordenamento territorial agrícola brasileira, mantêm-se até hoje como palco de conflitos e relações de poder, já que as relações de opressão permanecem incidindo sobre a população negra quilombola. $O$ racismo 
institucional, como racismo de Estado, é um elemento que dá visibilidade à lógica biopolítica de "domínio sobre a vida que o poder se incumbiu" (Foucault, 2005, p. 304).

Trata-se, portanto, de uma lógica que expõe ao risco e elege as populações-alvo do adoecimento, da desproteção, da desfiliação, ou até mesmo de morte. Isto é, para quem o Estado vai ausentar-se de suas funções de proteção e seguridade social. As condições precárias de vida e trabalho que marcam o cotidiano dos territórios quilombolas, decorrentes da lógica de marginalização que, quando não alcança a morte física, "simplesmente impõe a morte política", com a expulsão ou a rejeição social e segregacionista (Foucault, 2005, p. 306), é a realidade que destacamos neste trabalho.

No caso da comunidade estudada, as lideranças relatam que, até o processo de reconhecimento como "remanescentes quilombolas", a situação era de extrema penúria, com a frequente ameaça de perda de parte das terras ocupadas, e a necessidade de submeter-se a qualquer tipo de trabalho, perpetuando as condições de exploração, e impossibilitando o alcance de um certo grau de autonomia pelo uso da própria terra.

Hoje a gente tá na luta atrás do título definitivo, porque na época os nossos antepassados, a gente passou, eles... Eu digo a gente porque eu passei a mesma coisa: passou muita dificuldade na época. E eles trocava uns "pedacinho"... Chega "cumpade" eu te dou um saco de farinha e ponho a cerca mais pra aqui, sabe? Foi tomando... Outro "cumpade" foi ficando com outra coisinha... Hoje muito dos "quilombola" que moram aqui não têm onde trabalhar, porque deu a terra em troca de farinha, de feijão pro outro né? (Liderança 1).

Nesse sentido, é importante destacar que as dificuldades em obter a titulação da terra podem ser agravadas com o progressivo desmonte no campo dos direitos sociais levado a cabo pelos últimos governos, e em grande parte pela bancada parlamentar conservadora, notadamente a chamada "bancada ruralista". Desde 2000, tramita na Câmara dos Deputados uma proposta de Emenda Constitucional (n. 215/00), de origem do Partido dos Democratas, que propõe alterar a redação do art. 68, do Ato das Disposições Constitucionais Transitórias, propondo a inclusão nas atribuições exclusivas do Congresso 
Nacional a responsabilidade pelas novas demarcações das terras indígenas e quilombolas, e pela ratificação ou não das demarcações já homologadas.

Para Nascimento, Batista e Nascimento (2016), tal proposta fere o caminho trilhado nos avanços dos direitos das comunidades tradicionais, nos âmbitos nacional e internacional, além de desconsiderar a exigência de um trabalho técnico e especializado, como é o caso dos relatórios produzidos por antropólogos, que garantem "tornar compreensível (traduzir) os saberes e os modos próprios de construção de um universo simbólico constituído, de modo a garantir esse direito" (Nascimento, Batista \& Nascimento, 2016, p. 441). A ação do Partido dos Democratas foi recentemente julgada pelo Superior Tribunal Federal/STF. Na oportunidade foi organizada uma ampla campanha, com envolvimento dos movimentos sociais negros, intitulada "O Brasil é Quilombola, Nenhum Quilombo a Menos", em defesa do Decreto n. 4.887, que regulamenta os procedimentos para identificação, reconhecimento, delimitação, demarcação e titulação das terras ocupadas. Apesar do ganho de causa no STF na manutenção do Decreto, é preciso que os movimentos continuem em alerta e organizados para as muitas lutas que estão por vir.

É visível, pois, a fragilidade e a ameaça iminente de violação dos direitos adquiridos nas últimas décadas pelas comunidades quilombolas. Essa instabilidade perpetua uma história de exclusão e desigualdade. As práticas de resistência continuam e se pautam na luta dos movimentos sociais negros para rever séculos de invisibilidade e negação da existência desses sujeitos, bem como a afirmação de seus direitos. Contudo, concordamos com Cunha (2014, p. 75), ao expor que, nessa esfera, a "questão quilombola" foi tomada por uma espécie de paradoxo: "ao mesmo tempo em que a inserção no ordenamento jurídico pode lhes trazer garantias emancipatórias, eles agora estão sujeitos às mais diversas intervenções arbitrárias do aparelho de Estado".

Como resistir faz parte da história dos quilombolas, entendemos que o autor também deixa algumas pistas de como a "identidade quilombola" poderia ser assumida, estrategicamente, em sua dimensão política, em vez de reduzir-se aos propósitos de intervenção e controle social. A identidade, nesse caso, é estratégica para, a partir das fronteiras que os povos quilombolas mantêm abertas frente a outros campos e estratégias 
de luta, como recompor forças com outros povos tradicionais, movimentos sociais, sindicatos, universidades e sociedade em geral, para somar às lutas e estratégias de ação pela manutenção e garantia de direitos, criando novos agenciamentos diante da biopolítica. Além de ações voltadas para produzir deslocamentos em meio às estruturas de poder e domínio do Estado, seria estratégico investir, por dentro dos movimentos, nos "jogos de apropriação de força-sobre-força" (Cunha, 2014, p. 26) no objetivo de operar ações de contraconduta, tal qual indicou Foucault (2008) no curso "Segurança, Território e População".

Considerando que "viver em sociedade é, de qualquer maneira, viver de modo que seja possível a alguns agirem sobre a ação dos outros" (Foucault, 1995, p. 246), as ações de contracondutas, nesse sentido, constituem-se em investimentos de contrapoderes para deslocar determinados campos de força e fazer "emergir novas formas de condução" (VeigaNeto \& Lopes, 2011 , p. 5) na micropolítica do cotidiano da vida que resistam e desloquem práticas de governo, historicamente, marcadas pela dominação, segregação e o silenciamento do que difere.

\section{Considerações finais}

Esse artigo tratou de acompanhar alguns dos processos históricos, sociais, culturais e políticos, a partir de perpassamentos macro e micropolíticos, como forma de reconhecer diferentes níveis de necessidade e situações de vulnerabilidade que marcam as condições de vida e acesso às políticas públicas da localidade investigada. Destacamos a intrínseca associação entre raça e classe social na produção das iniquidades e desigualdades que a população negra e em condição de pobreza vivencia, tornando-se uma evidente fronteira que dificulta o acesso à garantia de direitos e processos de mobilidade social. Desse modo, entendemos que o racismo institucional se configura como um bem-sucedido mecanismo da biopolítica ao produzir subjetividades que, paradoxalmente, sobrevivem entre a captura e a resistência. 
Além disso, sinalizamos como desafios e possíveis limitações enfrentadas neste estudo: as distâncias a serem percorridas com o deslocamento até a comunidade investigada; o acesso precário; a necessidade de planejar a etapa de campo levando em consideração a logística, o tempo e orçamento disponível. Por outro lado, certos cuidados, como apresentar e pactuar as etapas do trabalho de campo, reduzir possíveis ruídos na comunicação quanto aos objetivos da pesquisa e o papel dos pesquisadores, atentar-se para o uso de linguagem acessível e considerar o nível de escolaridade dos participantes e regionalismos utilizados. Essas foram estratégias importantes para viabilizar as ações de produção dos resultados da pesquisa.

Por fim, sugere-se o aprofundamento das questões abordadas, sob a perspectiva de delineamentos qualitativos e com maior tempo de imersão na etapa de campo, para o reconhecimento de processos psicossociais e de subjetivação política que contribuam com a construção de espaços que favoreçam o exercício da cidadania, a partir do estabelecimento de posturas dialógicas, cooperativas e problematizadoras da realidade investigada.

\section{Referências}

Bargas, J. K. R., \& Cardoso, L. F. C. (2015). Cartografia social e organização política das comunidades remanescentes de quilombos de Salvaterra, Marajó, Pará, Brasil. Boletim do Museu Paraense Emílio Goeldi. Ciências Humanas [online], 10(2), 469-488.

Biroli, F. (2018). Gênero e desigualdades: limites da democracia no Brasil. São Paulo: Boitempo.

Brasil (2003). Decreto n. 4.887, de 20 de novembro de 2003. (2003). Regulamenta o procedimento para identificação, reconhecimento, delimitação, demarcação e titulação das terras ocupadas por remanescentes das comunidades dos quilombos, de que trata o art. 68 do Ato das Disposições Constitucionais Transitórias. Brasília, DF: Casa Civil.

Brasil (2004). Programa Brasil Quilombola. Secretaria Especial de Políticas de Promoção de Igualdade Racial (Seppir). Brasília, DF: Abaré. Recuperado em 20 fevereiro, 2019, de http://bvsms.saude.gov.br/bvs/publicacoes/brasilquilombola_2004.pdf. 
Brasil (2007a). Decreto n. 6.040, de 7 de fevereiro de 2007. (2007). Institui a Política Nacional de Desenvolvimento Sustentável dos Povos e Comunidades Tradicionais. Brasília, DF: Casa Civil.

Brasil (2007b). Decreto n. 6.261, de 20 de novembro de 2007. (2007). Dispõe sobre a gestão integrada para o desenvolvimento da Agenda Social Quilombola no âmbito do Programa Brasil Quilombola e dá outras providências. Brasília, DF: Casa Civil.

Brasil (2014). Cadernos de Estudos: Desenvolvimento Social em Debate. Brasília, DF: Ministério do Desenvolvimento Social e Combate à Fome; Secretaria de Avaliação e Gestão da Informação.

Calheiros, F. P., \& Stadler, H. H. C. (2010). Identidade étnica e poder: os quilombos nas políticas públicas brasileiras. Rev. Katál Florianópolis, 13(1), 133-139.

Caponi, S. (2016). Viver e deixar morrer: biopolítica, risco e gestão das desigualdades. In M. Nalli \& S. R. V. Mansano (Orgs.). Michel Foucault: desdobramentos (pp. 229-246). SP: Autentica.

Cardoso, L., \& Gomes, L. (2011). Movimento social negro e movimento quilombola: para uma teoria da tradução. In XI Congresso Luso Afro Brasileiro de Ciências Sociais, Bahia, Brasil, ago., 2011.

Carvalho, A. P. C. (2016). Tecnologias de governo, regularização de territórios quilombolas, conflitos e respostas estatais. Horizontes Antropológicos, 22(46), 131-157.

Carvalho, S. R. (2009). Reflexões sobre o tema da cidadania e a produção de subjetividade no SUS. In S. C. Resende, S. Ferigato \& M. E. Barros (Orgs.). Conexões: saúde coletiva e políticas de subjetivação (pp. 23-41). São Paulo: Hucitec.

Cascais, A. F. (2016). Da biopolítica após Foucault: sustentabilidade dos sistemas e vidas insustentáveis. In M. Nalli \& S. R. V. Mansano (Orgs). Michel Foucault: desdobramentos (pp. 173-198). São Paulo: Autentica.

Creswell, J. W. (2007). Projeto de pesquisa: métodos qualitativo, quantitativo e misto. Porto Alegre: Artmed. 
Cunha, C. F. C (2014). Conexões entre Gilles Deleuze, a etnologia e as sociedades quilombolas do Vale do Ribeira. Dissertação de mestrado, Escola de Filosofia, Letras e Ciências Humanas, São Paulo, São Paulo, Brasil.

Deleuze, G., \& Guattari, F. (1996). Mil Platôs: capitalismo e esquizofrenia (Vol. 3). Rio de Janeiro: Ed. 34

Deleuze, G., \& Guattari, F. (1997). Mil Platôs: capitalismo e esquizofrenia (Vol. 5). Rio de Janeiro: Ed. 34

Duarte, A. (2008). Sobre a biopolítica: de Foucault ao século XXI. Disponível em http://www.revistacinetica.com.br/cep/andre_duarte.pdf.

Farhi Neto, L. (2008). Biopolítica como tecnologia de poder. Revista Internacional Interdisciplinar INTERthesis, 5, 47-65.

Ferreira-Neto, J. L. (2015). Micropolítica em Mil Platôs: uma leitura. Psicologia USP, 26(3), 397-406.

Foucault, M. (1995). O sujeito e o poder. In H. Dreyfus \& P. Rabinow. Michel Foucault, uma trajetória filosófica. Para além do estruturalismo e da hermenêutica (pp. 231-249). Rio de Janeiro: Forense Universitária.

Foucault, M. (2005). Em defesa da sociedade: curso no Collège de France (1975-1976). São Paulo: Martins Fontes.

Foucault (2008). Segurança, território, população: curso dado no College de France (19771978). São Paulo: Martins Fontes.

Furtado, M. B., Pedroza, R. L. S., \& Alves, C. B. (2014). Cultura, identidade e subjetividade quilombola: uma leitura a partir da Psicologia cultural. Psicologia \& Sociedade, 26(1), $106-115$.

Gohn, M. G. (1995). História dos movimentos e lutas sociais: a construção da cidadania dos brasileiros. São Paulo: Loyola.

Guattari, F., \& Rolnik, S. (2005). Micropolítica: cartografias do desejo. Rio de Janeiro: Vozes.

Haesbaert, R. (2007). O mito da desterritorialização: do "fim dos territórios" à multiterritorialidade. Rio de Janeiro: Bertrand Brasil. 
Leite, I. B. (2008). O projeto político quilombola: desafios, conquistas e impasses atuais. Estudos Feministas, 16(3), 965-977.

Little, P. (2002). Territórios sociais e povos tradicionais no Brasil: Por uma antropologia da territorialidade. Simpósio "Natureza e Sociedade: desafios epistemológicos para a Antropologia", Reunião Brasileira de Antropologia, Gramado, Rio Grande do Sul, Brasil.

López, L. C. (2012). O conceito de racismo institucional: aplicações no campo da saúde. Interface - Comunic, Saúde, Educ, 16(40), 121-134.

Marques, C. E. (2008). Remanescentes das comunidades de quilombos: da ressignificação ao imperativo legal. Dissertação de mestrado, Faculdade de Filosofia e Ciências Humanas da Universidade Federal de Minas Gerais, Belo Horizonte, Brasil.

Marques, C. E., \& Gomes, L. (2013). A Constituição de 1988 e a ressignificação dos quilombos contemporâneos: limites e potencialidades. Revista brasileira de ciências sociais, $28(81), 137-153$

Mbembe, A. (2017). Políticas da inimizade. Portugal: Antígona

Minayo, M. C. S. (2007). O desafio do conhecimento: pesquisa qualitativa em saúde (10a ed.). São Paulo: Hucitec.

Munanga, K. (1996). Estratégias e políticas de combate à discriminação racial. São Paulo: Editora da Universidade de São Paulo: Estação Ciência.

Nascimento, G. A. R., Batista, M. R. R., \& Nascimento, M. A. R. (2016). Panorama atual de proteção de direito à terra das comunidades quilombolas e desafios futuros. Interações, $17(3), 432-477$.

Neiva, A. C. G. R., Sereno, J. R. B., Santos, S. A., \& Fioravanti, M. C. S. (2008). Caracterização socioeconômica e cultura da Comunidade Quilombola Kalunga de Cavalcante, Goiás, Brasil: dados preliminares. In Simpósio Nacional Cerrado. Brasília, DF: Embrapa Cerrado.

Nunes, E. (2010). A gramática política do Brasil. Rio de Janeiro: Garamond.

Oliveira, F. B., \& D’Abadia, M. I. V. (2015). Territórios quilombolas em contextos rurais e urbanos brasileiros. Élisée, 4(2), 257-275. 
Rabinovich, E. P., \& Bastos, A. C. S (2007). O Carmo ou porque um quilombo não quer ser um quilombo. Revista Psicologia Política, 7(14), Recuperado em 20 fevereiro, 2019, de http://pepsic.bvsalud.org/pdf/rpp/v7n14/v7n14a10.pdf.

Reis, J. J., \& Gomes, F. S. (1996). Liberdade por um fio: História dos quilombos no Brasil. São Paulo: Companhia das Letras.

Santana, J. A., \& Moura, A. R. (2013). Do Hamlet edipianizado à ecologia mental e social: reflexões sobre segmentaridade molar e molecular. Revista Graphos, 15(2), 45-56.

Sauer, S. (2016). Luta pela terra e Reforma Agrária: a construção de espaços de cidadania no Brasil. In M. Dimenstein, J. Leite, J. P. Macedo \& C. Dantas (Orgs.). Condições de vida e saúde mental em contextos rurais (pp. 45-69). São Paulo: Intermeios.

Silva, J. T. (2009). O riacho e as eras: memórias, identidade e território em uma comunidade rural negra no Seridó Potiguar. Dissertação de mestrado, Programa de Pós-Graduação em História Social, Ceará, Brasil.

Silva, S. R. (2011). A trajetória do negro no Brasil e a territorialização quilombola. Disponível em http://www.reformaagrariaemdados.org.br/sites/default/files/1801-5350-1PB.pdf.

Valentim, R. P. F, \& Trindade, Z. A (2011). Modernidade e comunidades tradicionais: memória, identidade e transmissão em território quilombola. Revista Psicologia Política, $17(22), 295-308$.

Veiga-Neto, A., \& Lopes, M. C. (2011). Governamentalidade, biopolítica e inclusão. In R. A. C. Salcedo \& D. L. M. Días (Orgs.). Gubernamentalidad y educación: discusiones contemporâneas (pp. 105-122). Bogotá: IDEP.

Werneck, J. (2013). Racismo Institucional: uma abordagem conceitual. Geledés: São Paulo.

Recebido em: 2/4/2018

Aprovado em: 11/4/2019 